\title{
Equidade e saúde mental: desafios do trabalho do psicólogo com as pessoas surdas
}

\author{
Equity and mental health: challenges for the psychologist's work with people with deaf people \\ Equidad y salud mental: desafíos para el trabajo del psicólogo com personas com personas sordas
}

Recebido: 23/03/2021 | Revisado: 02/04/2021 | Aceito: 08/04/2021 | Publicado: 18/04/2021

\author{
Camila da Silva Riterbusche \\ ORCID: https://orcid.org/0000-0002-0900-349X \\ Universidade Franciscana, Brasil \\ E-mail: camilariterbusche@yahoo.com.br \\ Gabriela Maffini \\ ORCID: https://orcid.org/0000-0001-9130-4699 \\ Universidade Franciscana, Brasil \\ E-mail: g_maffini@hotmail.com \\ Camila dos Santos Gonçalves \\ ORCID: https://orcid.org/0000-0002-0655-8895 \\ Universidade Franciscana, Brasil \\ E-mail: camila.gon.79@gmail.com
}

\begin{abstract}
Resumo
A audição é considerada como um sentido importante para inserção na sociedade. A privação deste sentido pode resultar na dificuldade da utilização de diversos serviços da saúde, como o da Psicologia, considerando como possíveis fatores, o despreparo profissional e dos ambientes que fazem parte do cotidiano do sujeito. Tendo em vista essa temática, este artigo possui como objetivo abordar os desafios encontrados no trabalho do psicólogo frente ao atendimento de pessoas surdas. Foi realizada uma pesquisa qualitativa, e o método utilizado consistiu em uma revisão narrativa de literatura. Os resultados foram divididos em três categorias: a equidade do cuidado, desafios no campo da saúde, e o atendimento psicológico com pessoas surdas. Diante da prática profissional, a dificuldade em compreender a linguagem de sinais pode apresentar-se como empecilho no atendimento a pessoas surdas não oralizadas. Algumas razões para tal empecilho estão relacionadas a falta contextualização sobre o uso da Libras nos cursos de graduação, a aprendizagem tardia sobre esta linguagem e a falta de interesse em capacitar-se por parte dos profissionais. Com este estudo, considera-se a importância de haver maior aprofundamento sobre o assunto, visto que, há uma necessidade de amparar, acolher e compreender as demandas deste público.
\end{abstract}

Palavras-chave: Perda auditiva; Psicologia; Saúde mental; Equidade em saúde; Direitos humanos.

\begin{abstract}
Hearing is considered an important sense for insertion in society. The deprivation of this sense can result in the difficulty of using several health services, such as Psychology, considering as possible factors, the professional unpreparedness and the environments that are part of the person daily life. In view of this theme, this article aims to address the challenges encountered in the psychologist's work in the care of people Qualitative research was carried out, and the method used consisted of a narrative literature review. The results were divided in three categories: equity of care, challenges in health, and psychological assistance to deaf people. In view of professional practice, the difficulty in understanding sign language can present itself as na obstacle in the care of deaf people who are not oralized. Some reasons for this obstacle are related to the lack of theoretical deepening about Libras in undergraduate courses, late learning about this language and the lack of interest in training by professionals. With this study, it is considered the importance of further studies on the subject, since there is a need to support, accept and understand the demands of this audience.
\end{abstract}

Keywords: Hearing loss; Psychology; Mental health; Health equity; Human rights.

\section{Resumen}

La audición se considera un sentido importante para la inserción en la sociedad. La privación deste sentido puede derivar en la dificultad de utilizar varios servicios de salud, como la Psicología, considerando como posibles factores, la falta de preparación profesional y los entornos que forman parte de la vida diaria del sujeto. En vista de este tema, este artículo tiene como objetivo abordar los desafíos encontrados en el trabajo del psicólogo en el cuidado de personas con discapacidad auditiva, usuários de la lengua de signos brasileña. Se realizó una investigación cualitativa y el método utilizado consistió en una revisión narrativa de la literatura. Como resultados encontrados, la bibliografía consultada muestra que, en vista de la práctica profesional, la dificultad para comprender la lengua de signos puede presentarse como un obstáculo en la atención de las personas sordas. Os resultados se dividieron em tres categorías: equidad em la atención, desafíos en salud e assistencia psicológica a personas sordas. A la vista de la práctica profesional, la dificultad para comprender la lengua de signos pode ser como um obstáculo en el cuidado de las 
personas sordas que no están oralizadas. Algunas razones de este obstáculo están relacionadas con la falta de profundización teórica sobre Libra en los cursos de pregrado, el aprendizaje tardío de este idioma y el desinterés por la formación de los profesionales. Con este estudio, se considera la importancia de una mayor profundidad en el tema, ya que existe la necesidad de apoyar, acoger y comprender las demandas de esta audiencia.

Palabras clave: Pérdida auditiva; Psicología; Salud mental; Equidad en salud; Derechos humanos.

\section{Introdução}

O compromisso social da psicologia precisa transparecer nas práticas cotidianas, e pode ser expresso através de uma atuação ética e política no combate às desigualdades sociais. Dentro disso, é relevante problematizar as formas de normatização e exclusão de determinados grupos, como o das pessoas surdas. As mudanças sociais frente aos grupos minorizados são perenes e oriundas de intensas lutas e articulações políticas. Neste sentido, é responsabilidade da psicologia se posicionar frente às desigualdades e buscar ampliar o acesso das pessoas aos serviços de saúde. E assim, contribuir com a sensibilização para as especificidades destes indivíduos sem enquadrá-los pelas suas diferenças.

A Lei $n^{\circ}$ 13.146/2015 do Estatuto da Pessoa com Deficiência reconhece a necessidade de assegurar e promover, em condições de igualdade, o exercício dos direitos e das liberdades fundamentais, visando a inclusão social e o exercício pleno de cidadania (Brasil, 2015). Este estatuto inclui pessoas com perdas no sistema auditivo, abrangendo aquelas que possuem perda parcial ou total da audição, de origem congênita ou adquirida, qual resulta na alteração da capacidade de compreender a fala, em função da privação (Coelho, Brasolotto, \& Bevilacqua, 2012).

A audição é apontada por Isaac e Manfrendi (2005), como um sentido importante na comunicação humana, sendo através dela que o sujeito adquire a linguagem. A privação desse sentido, segundo Borborema e Aguillera (2017), resulta na dificuldade da inserção na sociedade, podendo resultar na limitação ou prejuízo do acesso deste público a uma diversidade de serviços, podendo-se associar como causa o despreparo dos profissionais e dos ambientes que compõem o cotidiano do sujeito.

A Lei 10.436/2002, a qual reconhece a Língua Brasileira de Sinais (Libras) ${ }^{1}$ como meio legal de comunicação e de expressão, prevê que a Libras deve ser inserida como disciplina curricular obrigatória nos cursos de formação de professores para o exercício do magistério, estendendo-se para também o curso de Fonoaudiologia, entretanto, para os demais cursos de educação superior e profissional deverá ser inserida como disciplina optativa (Brasil, 2002). Ainda que exista a oferta da disciplina, há poucas oportunidades de seu exercício em atividades práticas, isto é, há falta de aprofundamento teórico e prático sobre Libras na formação dos demais profissionais da saúde, visto que, ela não é obrigatória em muitos cursos da graduação (Guarinello, Berberian, Eyng, Festa et al., 2012; Oliveira, Costa, Coura, Cartaxo, \& França 2012).

Apesar do avanço tecnológico - detecção e intervenção precoce, próteses auditivas, implante coclear, por exemplo - a utilização destes recursos não garantirá que as pessoas surdas serão oralizadas. Neste sentido, há desafios diferenciados conforme a modalidade de comunicação utilizada, seja oral ou língua de sinais. Especificamente no caso das pessoas não oralizadas, há uma ampla discussão da comunidade surda sobre como ampliar a compreensão da cultura surda e do uso da língua de sinais em diferentes espaços (Dizeu \& Caporali, 2005). Pois, mesmo sendo um marcador linguístico importante, a cultura surda não pode ser reduzida apenas ao uso da língua de sinais (Witchs \& Lopes, 2018).

Diante das dificuldades cotidianas apresentadas por aqueles com alteração auditiva, reconhece-se a importância da inserção da área de Psicologia, com o intuito de proporcionar amparo e acolhimento. Para Macêdo e Torres (2017), a surdez é compreendida pelos profissionais de Psicologia como diferença cultural, sendo de imensa importância, capacitar os

\footnotetext{
${ }^{1}$ A escrita da sigla utilizada neste artigo será conforme disposto na Lei n ${ }^{\circ} 10.436$, de 24 de abril de 2002, que utiliza a forma "Libras", apenas primeira letra maiúscula e sem acento (Brasil, 2002).
} 
profissionais da área, de forma que o atendimento para pessoas com perda auditiva, seja o mais especializado e acessível possível.

O Código de Ética do profissional da Psicologia prevê como princípio fundamental para atuação que "o psicólogo contribuirá para promover a universalização do acesso à população às informações, ao conhecimento da ciência psicológica, aos serviços e aos padrões éticos da profissão". Logo, práticas que negam o reconhecimento da diversidade ferem os direitos humanos, e por consequência, a ética profissional (CFP, 2005). Ainda que seja inferido no código que o profissional deverá promover a saúde e a qualidade de vida para as coletividades, evidencia-se a necessidade de maior preparo por parte dos profissionais da saúde para atender o público com perda auditiva (Gonçalves, 2011, Oliveira et al., 2012).

Ainda, o Conselho Federal de Psicologia (2005) aponta que o trabalho do psicólogo deverá ter base nos princípios da Declaração Universal dos Direitos Humanos, onde deverá trabalhar com a promoção de respeito, de liberdade, dignidade, igualdade e integralidade, recusando ser conivente com práticas que oprimam determinados públicos específicos, considerados como minorizados. Neste sentido, o presente artigo tem como objetivo abordar os desafios encontrados no trabalho dos/as psicólogos/as frente ao atendimento de pessoas surdas. Em especial, nos casos de pessoas surdas não oralizadas, visto que, um dos principais instrumentos de comunicação é a linguagem brasileira de sinais.

\section{Metodologia}

Este estudo trata-se de uma pesquisa qualitativa, e empregou uma revisão de literatura narrativa não sistemática. Denzin e Lincoln (2006), consideram que a pesquisa qualitativa envolve uma abordagem interpretativa em relação ao mundo, visando buscar uma compreensão sobre fenômenos em termos de significados atribuídos. A base de uma pesquisa qualitativa, para Minayo (2012), encontra-se na compreensão, buscando levar em consideração as subjetividades e identificações, tanto de quem lê, quanto de quem escreve. Este tipo de pesquisa, para Silva (2004), visa entender fenômenos complexos, de natureza social e cultural, seja mediante descrições, comparações ou interpretações. A revisão de literatura narrativa, segundo Rother (2007), engloba análise de publicações através da interpretação pessoal dos/as autores/as. São consideradas abrangentes, e visam descrever e discutir determinados assuntos. Diferentemente da revisão sistemática de literatura, a seleção de fontes da revisão narrativa não é especificada, e é por si, potencialmente tendenciosa por trata-se de uma organização intencional. Ainda de acordo com o autor, a revisão narrativa pode contribuir profundamente na discussão de determinadas temáticas, levantando questões e colaborando para aquisição de conhecimentos.

A questão norteadora deste estudo consiste em: "Quais os desafios encontrados no trabalho do psicólogo frente ao atendimento de pessoas surdas, não oralizadas?". Com a finalidade de investigar essa questão, levando em considerações as diferenças culturais existentes em diferentes países e a América do Sul, realizaram-se consultas não sistemáticas nas plataformas digitais como Pepsic (Periódicos Eletrônicos de Psicologia), Scielo (Scientific Eletronic Library) e Google Acadêmico (Google Scholar), além de serem utilizados capítulos de livros, trabalhos publicados em eventos e legislação nacional. Como critérios de inclusão foram priorizando-se artigos redigidos na língua portuguesa e espanhola, para que os resultados encontrados fossem mais condizentes com a realidade do Brasil.

Em relação aos critérios de exclusão, removeu-se artigos que não estivessem disponíveis de forma gratuita. Após a seleção do material, as pesquisadoras realizaram a leitura na íntegra do material selecionado intencionalmente conforme a questão norteadora do estudo. Posteriormente, os resultados foram organizados a priori em três categorias: a equidade do cuidado, desafios no campo da saúde, e o atendimento psicológico com pessoas surdas. 


\section{Resultados e Discussão}

\section{A equidade do cuidado}

O termo deficiência e todo o sentido que ele carrega, mesmo que impregnado de valores pejorativos e subordinados a normatização ainda é uma terminologia encontrada nas publicações e legislações, mas precisa ser problematizado. Segundo Fonseca (2007), o termo indica que as limitações físicas, mentais, intelectuais ou sensoriais são, muitas vezes, consideradas como atributos pertencentes às pessoas, que passam a sofrer restrições para os exercícios de seus direitos, padecendo diretamente das barreiras sociais ou culturais que se impõe a elas. Neste sentido, os/as profissionais de saúde têm o desafio de oferecer estratégias concretas para efetivar o acesso às informações e serviços para atender as necessidades de todos.

A trajetória dos termos utilizados ao longo da história passaram por transformações no Brasil, tanto em relação às nomenclaturas utilizadas quanto as formas de tratamento e serviços ofertados. De acordo com Sassaki (2003), de 1981 a 1987, pela primeira vez foi usado o termo "pessoas deficientes" no lugar de "deficientes", isto é, o termo pessoa ganha evidência, e busca salientar os aspectos legais inerentes para a garantia de direitos e dignidade desta população na sociedade. Posteriormente, de 1988 até 1993, inseriram "portadoras de" no termo anterior, demarcando uma delimitação da condição na vida das pessoas. Após, foi utilizado a nomenclatura de “pessoas com necessidades especiais” ou até mesmo “pessoas especiais", também revista pela ambiguidade de sentidos inerentes. Em 1994, a Declaração de Salamanca tratou a educação inclusiva como algo direcionado para todas as pessoas que apresentassem necessidades educacionais especiais. A nomenclatura atual, elaborada com a participação ativa da sociedade é "pessoas com deficiências".

Uma pessoa é considerada surda quando apresenta algum problema estrutural ou sensorial no sistema auditivo, tendo assim, uma redução ou ausência ao ouvir determinados sons. Em outras palavras, esta dificuldade faz com que a pessoa tenha alterada a capacidade de receber, associar, discriminar e compreender os sons, e com isso, limitações no processo de aprendizagem da escuta, mesmo com o uso de dispositivos especiais (Quiñónes et al., 2009). As pessoas surdas não fazem parte de um grupo homogêneo, é importante salientar que existe diferentes tipos de perdas auditivas, e consequentemente, formas singulares de compreensão das condições e modos de existência de cada pessoa.

O conceito de equidade envolve a concepção de que todas as pessoas devem ter oportunidades justas, com o intuito de ocorrer a redução das disparidades que podem ser evitadas, para o sujeito atingir o seu potencial de saúde. E, a integralidade nas práticas de saúde impele o exercício de alteridade, visto que a produção em saúde se estabelece nas relações com as diferentes perspectivas, que interferem no modo como o cuidado é prestado (Siqueira, Hollanda, \& Motta, 2017). No Brasil, o Sistema Único de Saúde (SUS) tem como uma de suas diretrizes a equidade, em que se baseia no atendimento aos indivíduos de acordo com suas necessidades. Neste sentido, é relevante pensar na necessidade de ampliar os canais de acesso aos serviços de saúde e possibilitar melhores condições de comunicação das necessidades das pessoas surdas (Cardoso, Rodrigues, \& Bachion, 2006).

Considera-se a interseccionalidade como uma das ferramentas teórico-metodológicas que permitem a compreensão das opressões vivenciadas por determinados povos específicos. Dentro do contexto brasileiro, esta ganhou espaço através de discussões sobre gênero e raça, pois permite que exista compreensão e reflexões acerca das desigualdades existentes e os lugares ocupados pelas minorias (Assis, 2019). Para a autora Hirata (2014), a interseccionalidade é vista como uma das formas de combater as opressões múltiplas e enraizadas, sendo um instrumento de luta política. Ambos os conceitos, equidade e interseccionalidade, se interligam por destacarem a existência de desigualdades e a necessidade das instituições criarem recursos para combate-las.

A Constituição de 1988 e o Estatuto da Criança e do Adolescente, possuem em seu conteúdo, leis e artigos que visam a garantia de equidade e de direitos para as pessoas surdas (Mariani, Santos, \& Silva, 2016), entretanto, na prática, há disparidades no que deveria ser garantido e sobre o que é realmente ofertado para pessoas que apresentam esta condição. Neste 
sentido, é preciso fortalecer na formação profissional o agir ético-político em defesa da garantia de acesso a informações e serviços de saúde pelas pessoas surdas. Sendo assim, a equidade seria alcançada a partir do reconhecimento e preparo dos profissionais para suas especificidades. Além disso, considerar a interseccionalidade que compõe os modos de vida desse público.

\section{Desafios no campo da saúde}

A garantia de direitos e acessibilidade das pessoas com deficiência é um tema que se encontra presente nas pautas da gestão pública, e já houve muitas conquistas em relação ao aumento de informações sobre essa temática (Barnes, 2009), em especial para os profissionais de saúde. A inclusão das pessoas é uma questão coletiva e que precisam de respostas no âmbito público, sendo essencial que exista na legislação dos países, leis que garantam o exercício dos direitos humanos para as pessoas neste contexto. Tais como, a concepção de espaços, programas, políticas, serviços e produtos de forma universal e inclusiva, e não construir obstáculos que impeçam a participação dessa população em qualquer atividade (Lopes, 2014). Para sua maior compreensão, faz-se necessário difundir e refletir sobre as formas de olhar para as necessidades e potencialidades específicas das pessoas, e compreender seus múltiplos significados e os efeitos deles na oferta de informações e serviços.

Foi apenas em 1994 que o termo "Pessoas com Deficiência" passou a ser usado, mas ainda sem o consenso sobre a forma mais adequada para se referir as pessoas nestas condições. Os termos e significados atribuídos às pessoas vem mostrando constante modificações conforme o contexto e as mudanças geradas pela participação social. A linguagem é dinâmica, e a reflexão entre os movimentos sociais e trabalhadores da educação e saúde sobre as terminologias é constante, pelo fato de que em cada espaço e tempo haverá termos em que o significado expresse os valores de cada sociedade (Sassaki, 2003).

$\mathrm{Na}$ legislação nacional a deficiência auditiva é descrita como sendo "caracterizada pela perda total ou parcial da capacidade de ouvir, manifesta-se como surdez leve e moderada e surdez severa ou profunda" (Brasil, 2008, p.17). O Ministério da Saúde, instituiu a Política Nacional de Atenção à Saúde Auditiva através da Portaria GM n. 2.073/04, de 28 de setembro de 2004 (Brasil, 2008). O direito à saúde das pessoas surdas foi ampliado pelo decreto Lei $\mathrm{n}^{\circ} 5.626$ de 2005, que organizou o atendimento para este público na rede de serviços do SUS. Porém, esses usuários se deparam com a dificuldade de estabelecer uma efetiva comunicação interpessoal, desvelando o despreparo das equipes para o acolhimento adequado de suas necessidades (Tedesco \& Junges, 2013).

Logo, a alternativa da criação de serviços especializados, apensar de tentadora, corre o risco de produzir como efeito a segregação e patologização das diferenças, ao invés de adequar os serviços em geral para as especificidades da população surda. Segundo Villela (2008), a lógica dos serviços especializados "embora aparentemente inocente, evidencia o raciocínio excludente vigente na sociedade, e é assim que a "experiência de deficiência" se perpetua" (p.544). E ainda, segundo a autora, dificulta que as pessoas busquem a acessibilidade aos espaços sociais e o cumprimento de medidas de acesso igualitário a seus direitos.

O estranhamento e segregação das pessoas surdas não ocorre apenas pela população em geral, mas também, pelo despreparo de alguns profissionais. Logo, as equipes de saúde não deveriam ser parte do problema, mas uma das partes indispensável para o acolhimento adequado (Pereira \& Lourenço, 2017). Segundo Lieu et al., (2007), a relação dos profissionais da saúde com as pessoas surdas ainda apresenta muitas dificuldades, principalmente na parte de entendimento da linguagem apresentada pelos/as pacientes. Ainda que, alguns profissionais utilizem a Língua Brasileira de Sinais, evidencia-se claramente a dificuldade de compreensão como empecilho para a comunicação com as pessoas surdas.

Baelli, et al., (2011), citam as restrições do campo do ensino e do campo da saúde, pois os acessos a estas informações ocorrem predominantemente de forma sonora. Segundo a pesquisa de Lamberg e Oliveira (2017) as mulheres surdas são ainda 
mais prejudicas por não conseguirem acessar amplamente os mecanismos de cuidado em saúde devido ao não preparo das equipes. O estudo das autoras apontou que as mulheres surdas tinham dificuldades de denunciar violência doméstica, e de serem acolhidas pelas equipes de saúde. Para Tedesco e Junges (2013), as dificuldades na comunicação também provocam desconforto nos profissionais da saúde, como angústia e ansiedade, interferindo na qualidade do acolhimento. A pesquisa realizada por Bisol, Simioni e Sperb (2008) indicou a preocupação com a qualidade dos atendimentos em saúde da população surda, dentre eles, salientaram as pesquisas norte-americanas quanto a prevenção e tratamento de ISTs e HIV/aids por pesquisas.

É essencial que os profissionais também sejam amparados para atender as especificidades da população surda. Em função disso, é necessário que tenham acesso a formação continuada e recursos que contribuam para a comunicação (Brasil, 2015). Desta forma, ressalta-se que o adequado preparo e atualização permite que os serviços possam proporcionar a equidade na atenção em saúde. Logo, a integralidade do cuidado passa pela compreensão das particularidades da cultura surda, e o abandono da perspectiva restrita ao déficit e a reabilitação.

\section{O atendimento psicológico para a população surda}

A pesquisa sobre a análise das publicações brasileiras da psicologia no campo da surdez, realizada por Bisol, Simioni e Sperb (2008), aponta que assim como as demais áreas que se dedicam à surdez, há divergências quanto a compreensão da condição das pessoas surdas entre pesquisadores da psicologia. Enquanto alguns partem da noção de surdez enquanto deficiência e defendem a oralização dos surdos, outros são favoráveis à língua de sinais e do bilinguismo a partir da lógica de diferença cultural. Sendo que "os primeiros geralmente identificam-se com modelo clínico-terapêutico de surdez, enquanto os segundos defendem a concepção socioantropológica" (p.393).

Existe diversos desafios a serem enfrentados para a promoção de um atendimento de qualidade a essa população, sendo um dos grandes obstáculos encontrados na literatura, a falta de informação sobre o fenômeno da surdez, os estereótipos existentes e a não existência de uma priorização das demandas da população não oralizada nos serviços de saúde (Gonçalves, 2005). Sendo assim, a falta de compreensão sobre as angústias, expectativas e compreensão das experiências vivenciadas no cotidiano são uma realidade presente para as pessoas surdas. Logo, a Psicologia, que parte do pressuposto de contribuir para erradicar qualquer tipo de negligência, opressão ou exclusão, precisa estar preparada para compreender a condição de surdez como uma das formas de existência possível, e buscar a singularidade das experiencias (CFP, 2005).

Neste sentido, nos cursos de formação em psicologia deve ser oportunizado meios para esclarecer concepções estigmatizadas sobre as pessoas nestas condições, e assim instrumentaliza futuros profissionais para lidarem com a diversidade humana (Villela, 2008). Ao falar sobre o fenômeno da inclusão, se reconhece a existência de práticas que consolidam o olhar excludente da sociedade para a população com perda auditiva (Machado, Almeida, \& Saraiva, 2009). A forma como estes são vistos perpetua uma imagem errônea de capacitismo e dependência, resultando na escassez de recursos que compreendam as reais demandas dessa população (Silva \& Carmo, 2016). A surdez é definida por Pereira e Lourenço (2017, p. 5) "como uma condição heterogênea que engloba efeitos de longo alcance nos aspectos social, emocional e cognitivo do desenvolvimento das pessoas surdas". Entretanto, para que a compreensão de seus efeitos ocorra, há necessidade de haver contato com a comunidade surda, aproximação com seus pares, representatividade, pois a surdez tende a ser depreciada e vista apenas como uma barreira. O autor Gonçalves (2005) a partir da experiência com atendimentos de pessoas surdas afirma que não há diferenças qualitativas ou estruturais quanto ao psiquismo dessas pessoas, "mas ruídos que obstruem o fluxo da comunicação" (p.18). Em resposta, ele indica algumas estratégias que podem amenizar as diferenças comunicacionais como a ludicidade, o grafismo e os recursos eletrônicos. Além disso, salienta características como a forte expressividade como uma fonte rica para a escuta clínica. 
Os autores Dizeu e Caporali (2005), citam que o estigma, agrava-se cada vez que o sujeito enfrenta dificuldades em desempenhar atividades cotidianas que deveriam ser de fácil acesso. Esta questão redimensiona a importância da efetivação das políticas públicas, e do compromisso do campo da psicologia em contextualizar os obstáculos e as possibilidades em uma perspectiva social e de promoção de equidade, ao invés de restringir-se nas capacidades pessoais e familiares. Ainda de acordo com os autores, quando há a negligência e falta de informação, cria-se estigmas de que a surdez produz apenas limitações. Ao aprofundar estudos acerca da temática, conhecer a cultura do surdo, utilizar a linguagem de sinais, é uma das formas de auxiliar a integração das pessoas no tecido social coerente com sua forma de existir. Para que isso possa acontecer de fato, nota-se a necessidade de que o profissional da Psicologia esteja preparado para trabalhar com esse público a fim de disponibilizar um atendimento de qualidade dentro dos princípios éticos. Assim como previsto no Código de Ética da Profissão (CFP, 2005), que é de responsabilidade do psicólogo garantir acesso da população aos serviços de saúde mental.

Percebe-se a falta de aprofundamento teórico-prático sobre o tema no contexto acadêmico para os profissionais e estudantes envolvidos, incluindo a Psicologia. Apesar da existência da Lei 10.436/2002, que prevê a obrigatoriedade da disciplina de Libras nos cursos de formação de professores e Fonoaudiologia (Brasil, 2002), o uso optativo desta disciplina para cursos de Psicologia pode ser mais um entrave na atuação profissional com a população surda. Isso gera a clara evidência da dificuldade de compreensão da comunicação com o surdo (Lieu et al., 2007). Além disso, na revisão de literatura realizada por Pereira e Lourenço (2017), os autores constataram que na Psicologia existem poucos estudos sobre as especificidades do trabalho clínico com as pessoas surdas.

A existência da autonomia das universidades apoiada pela Lei de Diretrizes e Bases da Educação Nacional permite que elas definam a carga horária da disciplina. Os resultados encontrados na pesquisa realizada por Oliveira, Costa, Coura, Cartaxo e França (2012), demonstraram que para além do curso de Psicologia, outros cursos da área da saúde, como a Enfermagem, Fisioterapia e Odontologia também apresentam limitações em seus currículos de formação profissional. O domínio da Língua de Sinais, permite a aproximação com o paciente, compreendendo a existência de diversidade, legitimando seu sofrimento, reconhecendo o fenômeno da surdez como ele realmente é (Silva \& Carmo, 2016).

Há uma necessidade das universidades e dos profissionais da saúde trabalharem para preencher essa lacuna e contribuir para o desenvolvimento e inclusão da comunidade surda e de sua cultura (Camargos \& Ávila, 2019). Para isso seria importante trabalhar de forma mais efetiva em relação as equidades, e assim, potencializar competências e aprimorar recursos de comunicação para poder atender da melhor forma possível a comunidade surda.

Para o psicólogo estar apto para atender pessoas surdas ou com perda auditiva, a apropriação da linguagem de sinais é fundamental. A apropriação não se resume apenas ao fato de ter uma melhor comunicação com o paciente, mas também procurar entender as vivências dessa população (Cardoso, Rodrigues, \& Bachion, 2006). Visando contribuir com o assunto, Oliver Sacks (2010) cita em sua obra:

Na língua de um povo, observa Herder, 'reside toda a esfera de pensamento, sua tradição, história, religião e base da vida, todo o seu coração e sua alma'. Isso vale especialmente para a língua de sinais, porque ela é a voz - não só biológica, mas cultural, e impossível de silenciar - dos surdos (Sacks, 2010, p. 105)

A prestação de serviços para os surdos nos mostra uma reflexão ética difícil para os psicólogos a respeito da realização de uma prática em que haja clareza na comunicação entre o profissional e o paciente surdo. Como exemplo disso, podemos citar os problemas linguísticos existentes entre a linguagem do profissional e do paciente, ou a presença de um intérprete na sessão (Pereira \& Lourenço, 2017). Ainda, a presença de um terceiro pode interferir na omissão de detalhes acerca da real demanda do paciente (Silva \& Carmo, 2016). 
É importante reconhecer a relevância da qualificação do psicólogo no atendimento da comunidade surda e de sua cultura. Assim, considerar as pessoas de forma integralizada pressupõe uma escuta sensível e qualificada, que englobe todas as formas de expressão e comunicação das pessoas. É preciso preparar-se para escutar para além das palavras, e essa transformação social é papel de todos, porém o/a psicólogo/a ao dedicar-se a tal compromisso social também pode contribuir com a noção de pertencimento de uma população minorizada, de forma a instigá-la a ser protagonista de sua história.

Com base nas informações descritas ao longo do trabalho, é importante frisar que antes de pensar no sujeito e sua perda auditiva, é fundamental considerar que para além de um lugar de diferença existe uma pessoa, com sua trajetória, redes afetivas, anseios, e visões de mundo. Além disso, a compreensão da cultura surda é muito mais ampla do que o ensino da linguagem de sinais. É preciso assegurar os princípios básicos da Declaração Universal dos Direitos Humanos, promovendo respeito, liberdade, dignidade, igualdade e integralidade. Com isso, podemos refletir sobre a importância da capacitação na formação desses profissionais, proporcionando amparo e acolhimento para esta população.

\section{Conclusão}

A produção deste artigo surgiu de uma provocação aos estudantes de graduação sobre as necessidades de grupos específicos, e os meios para minimizar os obstáculos produzidos socialmente para o acesso da população aos serviços de saúde. O objetivo aqui foi abordar os desafios encontrados no trabalho dos/as psicólogos/as frente ao atendimento de pessoas surdas. Em especial, nos casos de pessoas surdas não oralizadas, visto que, um dos principais instrumentos de comunicação é a linguagem brasileira de sinais. Foi um estudo inicial, que não pretendeu esgotar o assunto, mas despertar um olhar crítico sobre os desafios no campo da psicologia visando a integralidade de cuidado.

Diante dos desafios no campo da saúde frente às necessidades das pessoas surdas é preciso revisar a compreensão limitante das pessoas que apresentam perda auditiva, e reconhecer as especificidades de acesso à informação e serviços que para esta população. Para tanto, é preciso ampliar a formação que inclua a aprendizagem contextualizada para um melhor cuidado através da comunicação qualificada. O despreparo profissional para o atendimento de pessoas surdas não oralizadas pode ser minimizada nos cursos de graduação, onde a aprendizagem da linguagem de sinais ainda se mantém opcional. Embora haja a existência de leis que preconizam a obrigatoriedade para determinados cursos, levanta-se os seguintes questionamentos: Mesmo que existam leis que promovam aos estudantes de Psicologia disciplinas de Libras, sejam elas optativas ou obrigatórias, que práticas são oportunizadas para relacionar tais conhecimentos com as práticas? Como inserir atividades curriculares para trabalhar com este público? São perguntas que podem ser discutidas em trabalhos futuros.

Aponta-se como fatores limitantes desta pesquisa, os poucos artigos publicados disponíveis nas bases eletrônicas, compreendendo que também poderia ter sido feito uma busca mais ampliada. Embora esta temática seja presente nas rotinas de trabalho, ainda não está familiarizada pelos estudantes e profissionais da área de Psicologia. Destaca-se a pertinência da inserção dessa pauta nos cursos de formação e na educação continuada nos serviços de saúde. Espera-se que este trabalho contribua para fomentar novas pesquisas que contemplem essa temática.

\section{Referências}

Assis, D. N. C. (2019). Interseccionalidades. Instituto de Humanidades, Artes e Ciências: Superintendência de Educação a Distância, UFBA.

Baelli, I. M. M., Canteiro, M. T. R., Dardet, C. A., Lago, E. F., \& Aroca, E. F. (2011). Comunidades surdas: pacientes ou cidadãos? Gaceta Sanitária, 25(1), $1-9$.

Barnes, C. (2009). Un chiste "malo": ¿rehabilitar a las personas con discapacidad en una sociedad que discapacita? In: Brogna, P. (Org.). Visiones e revisiones de la discapacidad. México: FCE, 101-122.

Bisol, C. A., Simioni, J., \& Sperb, T. (2008). Contribuições da Psicologia Brasileira para o Estudo da Surdez. Psicologia: Reflexão e Crítica, 21(3), 392-400. 
Borborema, C. S., \& Aguillera, F. (2017) Criança com deficiência auditiva e família: desafios e contribuições da Psicologia. Rev. Psicol. Diversidade e Saúde, 6(2), 133-137.

Brasil. (2015). Lei n. 13.146, de 6 de julho de 2015. Estatuto da pessoa com deficiência.

Brasil. (2008). Política nacional de saúde da pessoa portadora de deficiência. Ministério da Saúde.

Brasil. (2002). Lei $n^{\circ} 10.436$, de 24 de abril de 2002. Regulamento Dispõe sobre a Língua Brasileira de Sinais - Libras e dá outras providências.

Camargos, G., \& Àvila, L. (2019). A interface da psicologia com a surdez: uma revisão sistemática. Revista De Psicologia, 10(2), 148-158.

Cardoso, A. H. A., Rodrigues, K. G., \& Bachion, M. M. (2006). Percepção da pessoa com surdez severa e/ou profunda acerca do processo de comunicação durante seu atendimento de saúde. Revista Latino-Americana de Enfermagem, 14(4), 553-560.

Coelho, A. C., Brasolotto, A. G., \& Bevilacqua, M. C. (2012). Análise sistemática dos benefícios do uso do implante coclear na produção vocal. J. Soc. Bras. Fonoaudiol. v. 24(4), 395-402.

Conselho Federal de Psicologia - CFP (2005). Resolução CFP no 010/2005. Código de Ética Profissional do Psicólogo, XIII Plenário. Brasília, DF: CFP.

Dizeu, L. C. T. B., \& Carporali, S. A. (2005). A língua de sinais constituindo o surdo como sujeito. Educ. Soc. $26(91)$, 583-597.

Denzin, N., \& Lincoln, Y. (2006). O Planejamento da pesquisa qualitativa: teorias e abordagens. ArtMed.

Dizeu, L. C. T. B., \& Caporali, S. A. (2005). A língua de sinais constituindo o surdo como sujeito. Educação \& Sociedade, $26(91)$, 583-597.

Fonseca, R. T. M. (2007). A ONU e o seu conceito revolucionário da pessoa com deficiência. Site Prefeitura Municipal de Porto Alegre. http://www2.portoalegre.rs.gov.br/smacis/default.php?reg=4\&p_secao=96

Gonçalves, P. C. S. (2005). Linguagem do silêncio: psicanálise e surdez. Arqueiro, 12, 17-21.

Gonçalves, P. C. S. (2011). Atendimento psicológico para surdos. Arara Azul.

Guarinello, A. C., Berberian, A. P., Eyng, D. B., Festa, P. S. V., Marques, J. M., \& Bortolozzi, K. B. (2013). A disciplina de Libras no contexto de formação acadêmica em fonoaudiologia. Revista CEFAC, 15(2), 334-340.

Hirata, H. (2014). Gênero, classe e raça: interseccionalidade e consubstancialidade das relações sociais. Tempos soc., 26(1), 61-63.

Isaac, M. L, \& Manfrendi, A. K. S. (2005). Diagnóstico precoce da surdez na infância. Medicina, 38(3), 253-244.

Lamberg, D. T., \& Oliveira, G.T. S. (2017) Seminário Internacional Fazendo Gênero 11 :transformações, conexões e deslocamentos \&13thWomen’s Worlds Congress (Anais Eletrônicos).

Lieu, C. C., Sadler, G. R., Fullerton, J. T., \& Stohlmann, P. D. (2007). Communication strategies for nurses interacting with deaf patients. Medsurg Nursing Journal. 16(4), 239-45.

Lopes, L. F. (2014). Novos Comentários à Convenção sobre os Direitos das Pessoas com Deficiência. Brasília, Secretaria de Direitos Humanos da Presidência da República, Secretaria de Promoção dos Direitos da Pessoa com Deficiência.

Macêdo, L. S., \& Torres, C. R. V. (2017). Psicologia inclusiva: a importância do atendimento psicoterapêutico a pessoas surdas. I Seminário Luso-Brasileiro de educação inclusiva. Porto Alegre: RS.

Maciel, M. R. C. (2000). Portadores de deficiência: a questão da inclusão social. Em Perspectiva, 14(2), 51-56.

Machado, A.M., Almeida, I., \& Saraiva, L. F. O. (2009). Rupturas necessárias para uma prática Inclusiva. In Educação inclusiva: experiências profissionais em psicologia. Brasília: Conselho Federal de Psicologia, 21-36.

Mariani, R., Santos, M. P., \& Silva, F. A. (2016). Uma experiência de equidade e inclusão de surdos numa escola regular. Revista Digital Simonsen, Rio de Janeiro, 10(4), 112-124.

Minayo, M. C. S. (2012). Análise qualitativa: teoria, passos e fidedignidade. Ciênc. saúde coletiva, 17(3), 621-626.

Oliveira, Y.C.A., Costa, G. M. C., Coura, A. S., Cartaxo, R. O., \& França, I. S. X. (2012). A língua brasileira de sinais na formação dos profissionais de enfermagem, fisioterapia e odontologia no estado da Paraíba, Brasil. Interface - Comunic., Saúde, Educ., 16(43), 995-1008.

Pereira, B. A. M., \& Lourenço, L. M. (2017). Surdez e Psicologia Clínica: Contribuições da Literatura. https://www.psicologia.pt/artigos/ver_artigo.php?surdez-e-psicologia-clinica-contribuicoes-da-literatura\&codigo=A1118\&area=D15F

Quiñónez, E., Ramírez, P., Velásquez, R., \& Rey, P. (2009) Salud auditiva y comunicativa: módulo de capacitación. Instituto Nacional para Sordos, 13(3), 468-480.

Rother, E. T (2007). Revisão sistemática x revisão Narrativa. Acta. paul. enferm, 20(2), 5-6.

Sacks, O. (2010). O olhar da mente. Companhia das Letras.

Sassaki, R. (2003). Vida Independente: história, movimento, liderança, conceito, filosofia e fundamentos. RNR. 
Research, Society and Development, v. 10, n. 4, e48410414208, 2021

(CC BY 4.0) | ISSN 2525-3409 | DOI: http://dx.doi.org/10.33448/rsd-v10i4.14208

Silva, A. M. S., \& Carmo, M. B.B. (2016). Desafios na atenção psicológica a surdos utilizados da LSB em Salvador - BA. Revista Psicologia, Diversidade e Saúde, 5(2), 184-192.

Silva, C. R. (2004). Metodologia e organização do projeto de pesquisa. CEFET.

Siqueira, S.A.V., Hollanda, E., \& Motta, J.I.J. (2017). Políticas de Promoção de Equidade em Saúde para grupos vulneráveis: o papel do Ministério da Saúde. Ciência \& Saúde Coletiva, 22(5), 1397-1406.

Souza, R. M. (1998). Sujeito surdo e profissionais ouvintes: repensando esta relação. Estilos da Clínica, 3(4), 130-145.

Tedesco, J.R., \& Junges, J.R. (2013). Desafios da prática do acolhimento de surdos na atenção primária. Cad. Saúde Pública, 29(8), 1685-1689.

Villela, E. M. B. (2008). O papel do serviço-escola de psicologia no atendimento ao deficiente visual. Estudos de Psicologia, 25(4), 535-545.

Witchs, P. H., \& Lopes, M. C. (2018). Forma de vida surda e seus marcadores culturais. Educação em Revista, 34. 